\title{
Recent Advances in Assessment and Treatment in Kienböck's Disease
}

\author{
Karol Chojnowski ${ }^{+}$, Mikołaj Opiełka ${ }^{+}$,, Miłosz Piotrowicz $(D)$, Bartosz Kamil Sobocki (D), Justyna Napora (D), \\ Filip Dąbrowski *, Maciej Piotrowski and Tomasz Mazurek
}

check for updates

Citation: Chojnowski, K.; Opiełka, M.; Piotrowicz, M.; Sobocki, B.K.;

Napora, J.; Dabrowski, F.; Piotrowski, M.; Mazurek, T. Recent Advances in Assessment and Treatment in Kienböck's Disease. J. Clin. Med. 2022, 11, 664. https://doi.org/ $10.3390 /$ jcm 11030664

Academic Editor: Christian Carulli

Received: 6 December 2021

Accepted: 21 January 2022

Published: 27 January 2022

Publisher's Note: MDPI stays neutral with regard to jurisdictional claims in published maps and institutional affiliations.

Copyright: (C) 2022 by the authors. Licensee MDPI, Basel, Switzerland. This article is an open access article distributed under the terms and conditions of the Creative Commons Attribution (CC BY) license (https:// creativecommons.org/licenses/by/ $4.0 /)$.
Department of Orthopaedics and Traumatology, Faculty of Medicine, Medical University of Gdansk, 80-803 Gdansk, Poland; karole97@gumed.edu.pl (K.C.); mopielka@gumed.edu.pl (M.O.); piotrowicz.milosz@gumed.edu.pl (M.P.); b.sobocki@gumed.edu.pl (B.K.S.); justanapora@gmail.com (J.N.); maciejpiotr@gumed.edu.pl (M.P.); mazurek@gumed.edu.pl (T.M.)

* Correspondence: dabrowskif@gmail.com

+ These authors contributed equally to the work.

\begin{abstract}
Kienböck's disease is a rare disease described as progressive avascular osteonecrosis of the lunate. The typical manifestations include a unilateral reduction in wrist motion with accompanying pain and swelling. Besides recent advances in treatment options, the etiology and pathophysiology of the disease remain poorly understood. Common risk factors include anatomical features including ulnar variance, differences in blood supply, increased intraosseous pressure along with direct trauma, and environmental influence. The staging of Kienböck's disease depends mainly on radiographic characteristics assessed according to the modified Lichtman scale. The selection of treatment options is often challenging, as radiographic features may not correspond directly to initial clinical symptoms and differ among age groups. At the earliest stages of Kienböck disease, the nonoperative, unloading management is generally preferred. Patients with negative ulnar variance are usually treated with radial shortening osteotomy. For patients with positive or neutral ulnar variance, a capitate shortening osteotomy is a recommended option. One of the most recent surgical techniques used in Stage III Kienböck cases is vascularized bone grafting. One of the most promising procedures is a vascularized, pedicled, scaphoid graft combined with partial radioscaphoid arthrodesis. This technique provides excellent pain management and prevents carpal collapse. In stage IV, salvage procedures including total wrist fusion or total wrist arthroplasty are often required.
\end{abstract}

Keywords: Kienböck; wrist; lunate bone; osteonecrosis

\section{Introduction}

Kienböck's disease is described as avascular osteonecrosis of the lunate. The etiology of this disease remains unknown and controversial [1]. However, it is possible to determine factors that generally impact the risk of incidence. The anatomical risk factors include the shape of the lunate and distal radius, ulnar variance, the coverage of lunate by radius, the blood supply, the excessive intraosseous pressure, and the venous stasis [2]. Personal factors include age and gender, the associated diseases, the trauma-related factors, the social and environmental factors, and the association with osteonecrosis of other carpal bones [2]. Kienböck's disease is classified as rare and its prevalence is about 7 per 100,000 [3,4]. Kienböck's disease shows male predominance, with a peak incidence in patients aged 20-40 years [5]. Repetitive manual labor was reported as a risk factor but currently is recognized as a factor aggravating symptoms of an already established disease [6]. Usually one hand is affected; only $4 \%$ of cases of the disease are bilateral. It is known that there is an association between Kienböck's disease and type 1 diabetes mellitus, systemic lupus erythematosus, and Legg-Calve-Perthes disease [5]. On examination, painful swelling on the dorsal side of the lunate can be observed. Decreased range of motion and grip strength of the wrist are typical [7]. Treatment of Kienböck's disease varies, starting from conservative 
modalities to surgical procedures, although none of them is a gold standard. The algorithm of treatment depends on clinical and radiological symptoms [7]. The Lichtman scale is the most common radiological classification used to describe Kienböck's disease. In 2003, Goldfarb and colleagues proposed a new, improved Lichtman scale [8]. The arthroscopic classification was developed by Bain et al. It is based on the number of articular surfaces of the lunate and adjacent articulation, which are defined as non-functional [9].

\section{Staging}

The staging of Kienböck's disease depends mainly on radiographic evaluation [8]. However, vascularization (Schmitt) and cartilage (Bain) evaluation are also clinically relevant $[10,11]$. Proper classification of the disease is essential in choosing the right treatment for a patient with osteonecrosis of the lunate (Table 1, Figure 1). In stage I, the lunate maintains normal architecture and density, yielding normal plain radiographs [7]. However, on T1-weighted MR images, the signal is slightly decreased [5,12]. At this stage the lunate is often intensively enhanced after contrast application, reflecting bone marrow edema [5]. In Stage II, radiographs show increased lunate density and diffused sclerosis, however, the wrist's architecture is not compromised [5,8]. In Stage III the lunate collapses. In this stage hyperintensity of the lunate marrow can be seen on fluid-sensitive T2-weighted images [5]. In 1993, stage III was divided into two stages: 3A and 3B, and it was further modified in 2010 with the addition of stage 3C [5]. In stage IIIA the lunate is collapsed but its carpal alignment and height remain unchanged [7]. Stage IIIB is associated with articular collapse, proximal migration of the capitate, and scaphoid palmar flexion, reflected by a cortical "ring sign" on radiographs [12] (Figures 2 and 3). Stage IIIC is reserved for a complete coronal plane split, regardless of the lunate/wrist morphology [13]. Stage IV is a combination of lunate collapse and radiocarpal or midcarpal degenerative arthritis [13].

Table 1. Lichtman's classification.

\begin{tabular}{ccc}
\hline Stage & Radiographs & MRI \\
\hline I & Normal & $\begin{array}{c}\downarrow \text { T1 signal, lunate enhancement } \\
\text { after contrast administration }\end{array}$ \\
\hline II & Increased density without lunate collapse & $\downarrow$ T1 signal, variable T2 signal \\
\hline IIIA & Lunate collapse, Radioscaphoid angle $<60^{\circ}$ & $\downarrow$ T1 signal, variable T2 signal \\
\hline IIIB & $\begin{array}{c}\text { Lunate collapse with scaphoid palmar } \\
\left.\text { flexion (radioscaphoid angle }>60^{\circ}\right)\end{array}$ & $\downarrow$ T1 signal, variable T2 signal \\
\hline IIIC & $\begin{array}{c}\text { Lunate collapse with coronal lunate } \\
\text { fracture (chronic) }\end{array}$ & $\downarrow \mathrm{T} 1$ signal, variable T2 signal \\
\hline IV & $\begin{array}{c}\text { Lunate collapse with radiocarpal or } \\
\text { midcarpal degenerative arthritis }\end{array}$ & $\downarrow \mathrm{T} 1$ signal, variable T2 signal \\
\hline
\end{tabular}

The downward arrow represents decrease in T1 signal. 


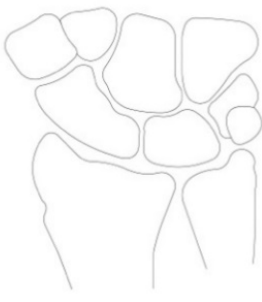

I

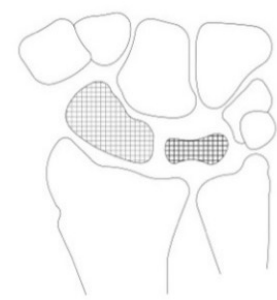

IIIb

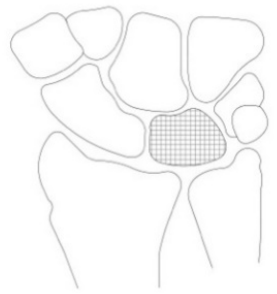

II

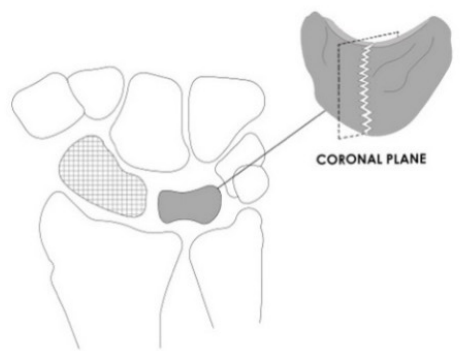

IIIc

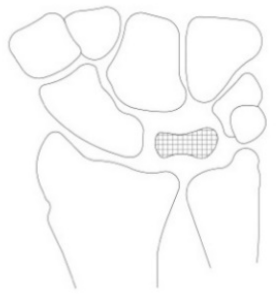

IIla

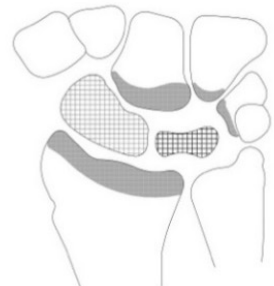

IV

Figure 1. A graphic representation of different stages of Kienböck's disease. In stage I lunate maintains normal architecture and density. Stage II is characterized by an increase in lunate density and diffused sclerosis of the lunate (visualized with a checkered pattern). In stage IIIa the lunate is collapsed but its carpal alignment and height remain unchanged (notice the decreased size of the lunate). In stage IIIb apart from lunate collapse, scaphoid palmar flexion occurs (visualized with a checkered pattern). Stage IIIc is reserved for complete coronal plane split (depicted as a bisection of the lunate). Stage IV is a combination of lunate collapse and radiocarpal or midcarpal degenerative arthritis (marked as grey areas on the articular surfaces of affected joints).

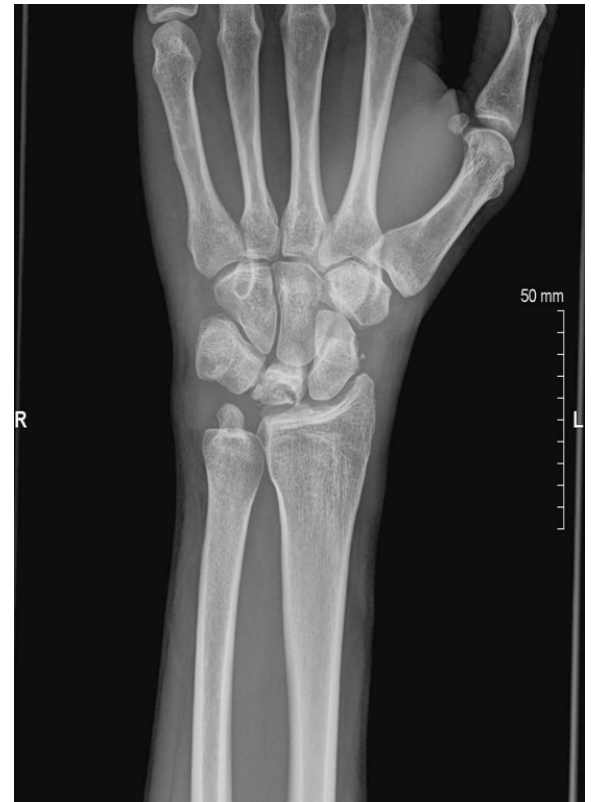

(a)

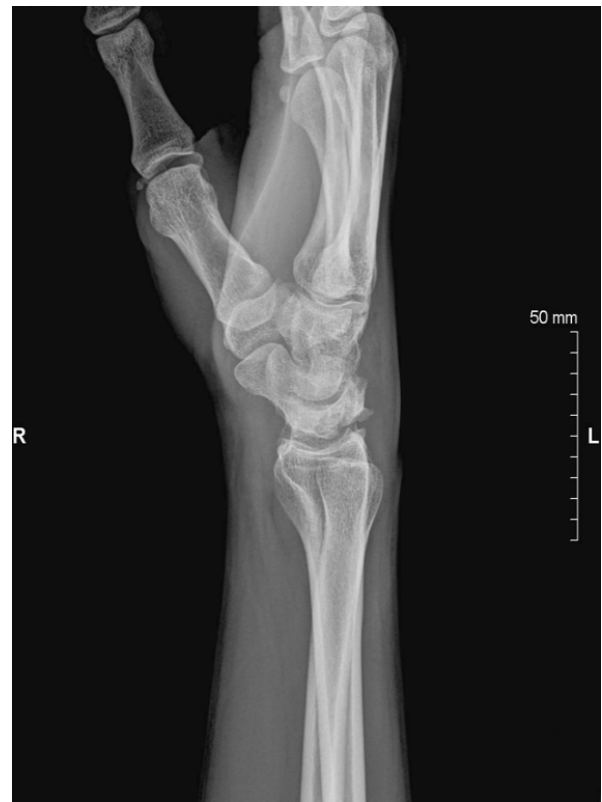

(b)

Figure 2. X-ray stage 3A: the collapse of lunate, carpal high preserved. (a) Stage 3A, AP view X-ray; (b) Stage 3A, lateral view X-ray. 


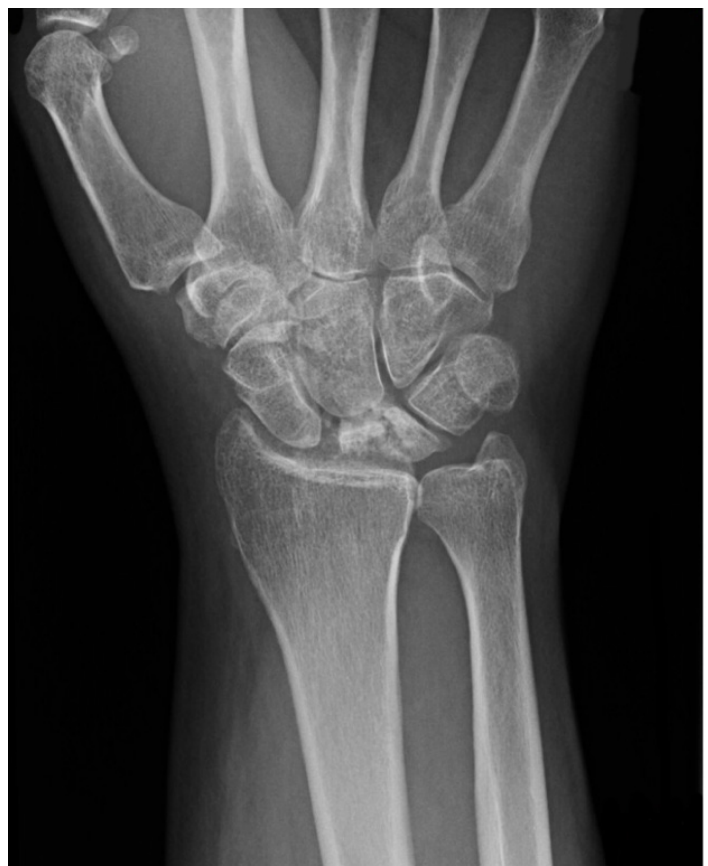

(a)

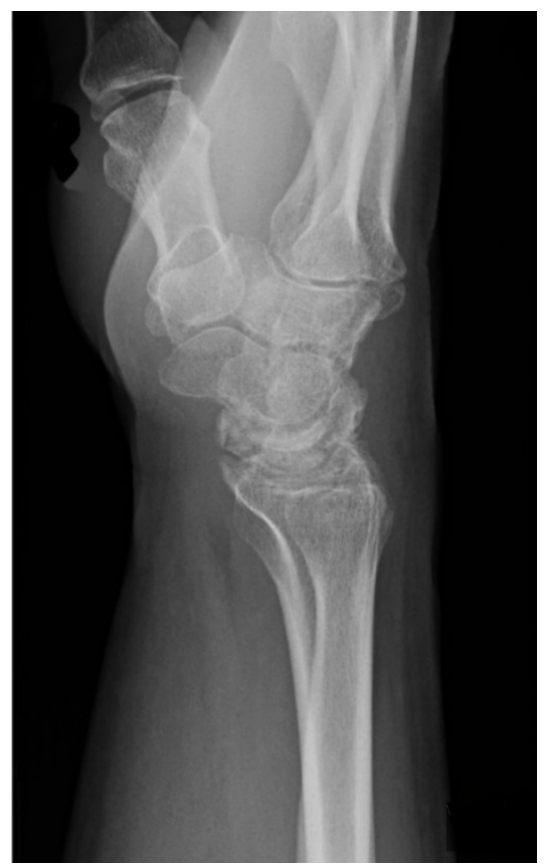

(b)

Figure 3. X-ray stage 3B: the collapse of lunate, carpal instability, scaphoid rotation, radioscaphoid angle (RSA) increased. (a) Stage 3B, AP view X-ray; (b) Stage 3B, lateral view -ray.

\section{Treatment in Early Stages (Lichtman Stages I, II, and III-A)}

The choice of treatment option for Kienböck's disease can be difficult, primarily due to the variety of factors that ought to be considered in the treatment procedure [7]. These factors include the patient's age, osseous assessment (Lichtman), ulnar variance, vascular assessment (Schmitt), and cartilage assessment (Bain) [14].

\subsection{Stage I (Lichtman Stage I)}

At the earliest stages of Kienböck disease, the management is usually nonoperative [14]. Immobilization with a splint or short arm cast (for at least three months) is the initial treatment option $[8,14]$. Even though Kienböck disease is a progressive disease, many patients treated conservatively stay functional with acceptable symptoms. Therefore, unless the patient remains symptomatic, no surgical interventions should be conducted [8]. In line with this notion, Brent et al. demonstrated a retrospective study involving 25 patients treated nonoperatively, where 12 wrists were in stage I. The study had a mean length of radiographic follow-up of 5.2 years and the observed progression in the Lichtman stage was $0.48 \pm 0.09$ stages per year. Importantly, despite the radiographic disease progression, nonoperational management improved pain, grip strength, and Mayo wrist score [15].

\subsection{Stage II (Lichtman Stage II, Bain 0, Schmitt Stage A)}

The three main treatment goals for stage II are lunate unloading, lunate decompression, and lunate revascularization $[8,13,14]$. Each patient with stage II should be matched with an individualized treatment method. Ulnar variance is a crucial factor that categorizes patients into two groups: negative-ulnar variance and neutral or positive ulnar variance [7]. Patients with negative ulnar variance are usually treated with radial shortening osteotomy [14]. The effectiveness of this method has been proven by Raven et al. in a study that involved 12 patients treated with radial shortening osteotomy with 22 years of follow-up. In this study a vast majority of patients had excellent pain relief and function [16]. A similar study with similar results has been conducted by Watanabe et al. with 13 patients and a follow-up of 21 years. In this study, 12 out of 13 patients noticed an improvement in terms of pain management [17]. However, according to Quenzer et al., radial shortening osteotomy com- 
bined with vascularized bone grafting achieves better results than joint-leveling procedure alone [18]. In line with this study, Daecke et al., with a long- term follow-up study, proved that radial shortening osteotomy along with vascularized pisiform bone grafting is an effective method in treating patients with negative ulnar variance [19]. Alternatively, the ulnar lengthening osteotomy can be considered. A few studies featuring long-term follow-up reported a good clinical outcome in patients treated with ulnar lengthening osteotomy [20,21]. In a biomechanical study conducted by Trumble et al., radial shortening osteotomy and ulnar lengthening achieved similar results regarding lunate strain [22]. Contrarily, the most recent study performed on cadavers showed more beneficial pressure distribution in preparations that underwent shortening of the radius compared to the lengthening of the ulna [23]. Overall, radial shortening osteotomy remains the most popular option regarding joint-leveling procedures [24]. This can be explained by the stronger scientific evidence favoring radial shortening and the occurrence of union-related complications associated with ulna lengthening $[14,16,17,25]$. For patients with positive/neutral ulnar variance, a capitate shortening osteotomy and radius wedge osteotomy are recommended options. Both of these methods mitigate revascularization by lunate unloading and achieving comparable clinical outcomes [13,14,26,27]. A different lunate-protective treatment method for stage II is lunate forage, which achieves lunate decompression [14]. It involves arthroscopic lunate drilling aimed at decreasing venous hypertension [28]. The advantage of this method is low invasiveness and therefore quick patient recovery. In a study involving 20 patients, treatment with lunate core decompression improved range of motion scores in all stage I and stage II cases [29]. Recently, a prospective cohort study involving 82 patients proved that arthroscopic lunate core decompression achieves comparable results to radial shortening osteotomy [30].

Apart from lunate unloading and lunate decompression, revascularization procedures play a vital role in treating stage II. The revascularization can be direct or indirect. The most notable indirect method of revascularization is core decompression of the distal radius/ulna [31]. The surgeon curettes cancellous bone of the distal metaphysis in the radius and ulna or in just the radius. This procedure initiates sufficient hyperemia for lunate revascularization. A series of studies conducted by Illarramendi et al. involving patients that underwent metaphyseal core decompression of both ulna and radius presented satisfying long-term follow-up results [32,33]. In line with this, 10 out of 12 patients in stages I and II that were treated with just radial metaphyseal core decompression achieved satisfactory midterm outcomes [34]. Overall, metaphyseal core decompression is an extra-articular and relatively simple operation with no reported complications [34]. Direct vascularization of the lunate can be achieved with a pedicled graft or free vascularized bone graft (VBG) [11]. VBG is the most frequently used method of treating stage II with neutral ulnar variance and the third most frequently used in stage I (in patients who failed immobilization) in the United States [24]. The popularity of this procedure is due to the amount of research that has proven the effectiveness of revascularization techniques [1,19,35-37]. The most popular VBG technique among American hand surgeons is VBG using the fourth and fifth extensor compartment arteries (ECA) [24]. The treatment aims at directing the fifth ECA with the retrograde flow into the 4th ECA with orthograde flow providing revascularization and remodeling of the avascular lunate [28]. Apart from the above-mentioned procedure, a vascularized pisiform bone transfer is also effective. Daecke et al., in their study of 23 patients with a mean follow-up of 12 years, revealed excellent results from this procedure. In 20 out of 23 patients there was a significant decrease in pain [19]. Other bone graft methods include volar radial graft, medial femoral condyle graft, the 1-2 inter compartmental artery, and the second dorsal metacarpal neck grafts $[37,38]$. In the most recent systematic review, which included 92 VBG-treated patients with Kienböck disease, all subjects achieved improvement in grip strength and pain with no effect on the range of motion. In cases treated with $4+5$ ECA graft, $71 \%$ achieved lunate revascularization, and in $15 \%$, progression of the disease was observed within a mean follow-up of 45 months [38]. 
It is important to mention that direct revascularization procedures are relatively more challenging for the surgeon and can result in the damaging of the articular surfaces due to the intra-articular nature of such treatment. Furthermore, lunate unloading/decompressionoriented procedures are simpler and offer comparable results.

\subsection{Stage IIIA (Lichtman Stage IIIA, Bain 1, Schmitt Stage B)}

At this stage the lunate is compromised, so the goal of the treatment should be set on lunate reconstruction via revascularization and/or unloading [14,25]. Of note, Patients in IIIA with negative ulnar variance benefit from joint leveling procedures similarly to patients in stage II [16]. Recently, an interesting approach was presented by Hong et al. in a study, where 18 patients in stage IIIA underwent radial wedge osteotomy in combination with radius shortening osteotomy. In this study, 16 cases of stage IIIA and two cases of stage IIIB achieved improvement regarding the range of motion of the wrist and pain. This method theoretically would allow patients with non-negative ulnar variance to benefit from radius shortening osteotomy similarly to patients with negative ulnar variance. Despite the promising results, a significant limitation of this study is the short follow-up period (22.3 months), thus lacking data covering disease progression rate/late occurring complications [39]. The recommended technique by Lichtman et al. is a vascularized medial femoral trochlea (MFT) graft [14]. Higgins et al. demonstrated satisfactory results in performing the MFT graft in patients at stage IIIA. In this study, in 15 out of 16 patients, CT affirmed healing [18]. Illarmendi et al. presented results from the treatment of 25 patients in stage IIIA with radius core decompression. Although satisfying results could be observed in most of the patients, the results were not as good as in patients in earlier stages [33]. However, more recently de Carli et al. presented a study that included 15 patients in stage IIIA that received radius core decompression. Fourteen out of 15 patients returned to their original employment and only two wrists progressed to later stages of the disease [17]. Apart from VBG, other viable surgical techniques are available such as proximal row carpectomy radioscapholunate fusion or scaphocapitate fusion [6-8]. The alternatives do not provide lunate reconstruction, and therefore are more destructive than lunate reconstruction-oriented procedures.

\section{Surgical Procedures in Late-Stage Patients (Lichtman IIIB, IIIC, and IV)}

There is a wide range of procedures that have been developed for the treatment of late-stage Kienböck disease throughout the years (Table 2). However, retrospective systemic reviews proved that none of the treatment options was superior concerning pain, grip strength, or motion measures [7]. Therefore, the most recent treatment algorithm recommends a highly individualized approach, taking the patient's age, state of the lunate, and state of the wrist into consideration [14].

In age groups younger than 15 years of age, those 16-20, and older than 70, nonoperative treatment is advisable in the first place regardless of the stage of the disease [14].

\subsection{Stage IIIB, IIIC}

This stage is characterized by the degeneration of the lunate articular surface and loss of the carpal height due to scaphoid flexion (radioscaphoid angle > 60) [53]. Because of the maintenance of radioscaphoid articulation, one of the main surgical procedures performed is Scaphocapitate (SC) fusion. The main target of this procedure is to stabilize the midcarpal joint and unload the lunate, preventing it from collapsing [8].

Alternatively to SC fusion, scaphotrapezio-trapezoid (STT) fusion can be performed [14]. Unfortunately, the effectiveness and reliability of these methods are differentiated. Early studies demonstrated satisfactory clinical results of performing STT procedures in Lichtman stage III patients [42]. However, recent articles showed that the STT procedure may cause severe pain, partial loss of mobility, and longer rehabilitation time compared to non-invasive treatment $[54,55]$. Radioscapholunate (RSL) arthrodesis is a partial fusion procedure which 
preserves the motion of the midcarpal joint and can provide significant pain relief. This procedure is particularly recommended in patients with arthritis of the metacarpal joint [43].

Table 2. Recommended treatment strategies for each stage of Kienböck disease.

\begin{tabular}{|c|c|c|c|}
\hline \multirow{2}{*}{$\begin{array}{l}\text { Stage of Kienböck's } \\
\text { Disease in Lichtman } \\
\text { Scale }\end{array}$} & \multirow{2}{*}{ Sub-Stage } & \multicolumn{2}{|r|}{ Leading Treatment } \\
\hline & & Aim of Treatment & Procedure \\
\hline $\mathrm{I}$ & & Preventing progression [14] & $\begin{array}{l}\text { Usually nonoperative (immobilization with a splint or } \\
\text { short arm cast for at least three months) }[14,15]\end{array}$ \\
\hline \multirow{2}{*}{ II } & $\begin{array}{l}\text { With a negative ulnar } \\
\text { variance }\end{array}$ & $\begin{array}{l}\text { Lunate unloading, decompression } \\
\text { and revascularization [14] }\end{array}$ & $\begin{array}{c}\text { radial shortening osteotomy (selectively or with } \\
\text { vascularized pisiform bone grafting) }[16-18] \text { or lunate } \\
\text { core decompression }[29,30]\end{array}$ \\
\hline & $\begin{array}{l}\text { With a positive or } \\
\text { neutral ulnar } \\
\text { variance }\end{array}$ & $\begin{array}{l}\text { Lunate unloading, decompression } \\
\text { and revascularization [14] }\end{array}$ & $\begin{array}{c}\text { capitate shortening osteotomy or radial closing wedge } \\
\text { osteotomy }[26,27] \text { or lunate core decompression }[29,30] \\
\text { And/or revascularization indirect: radial core } \\
\text { decompression }[33,34] \text { or direct: VBG } 4+5 \text { ECA }[37,38]\end{array}$ \\
\hline \multirow{3}{*}{ III } & A & $\begin{array}{l}\text { Lunate reconstruction through } \\
\text { lunate unloading and } \\
\text { revascularization }[14,25]\end{array}$ & $\begin{array}{c}\text { With negative ulnar variance: } \\
\text { radial shortening osteotomy [16-18] and/or } \\
\text { revascularization indirect: radial core decompression } \\
{[33,40] \text { or direct: VBG } 4+5 \text { ECA [37,38] or }} \\
\text { Vascularized medial femoral trochlea graft (MFT) [41] } \\
\text { With positive or neutral ulnar variance: } \\
\text { radial closing wedge osteotomy [26] and/or } \\
\text { revascularization indirect: radial core decompression } \\
{[33,40] \text { or direct: VBG } 4+5 \text { ECA }[37,38]}\end{array}$ \\
\hline & B & Preventing carpal collapse [8] & \multirow[b]{2}{*}{$\begin{array}{l}\text { Choice according to a highly individualized approach } \\
\text { among: } \\
\text { - Scaphocapitate (SC) fusion [8] } \\
\text { - Scaphotrapezio-trapezoid (STT) Fusion [42] } \\
\text {-Radioscapholunate (RSL) arthrodesis [43] } \\
\text { - Proximal Row Carpectomy (PRC) [44-46] } \\
\text { - Vascularized capitate transposition +/ - capitate } \\
\text { osteotomy combined with the vascularized bone transfer } \\
\text { (modified Granner's method) in late-stage Kienböck's } \\
\text { disease [47,48] } \\
\text { - Bone marrow transfusion combined with low-intensity } \\
\text { pulsed ultrasound [49] }\end{array}$} \\
\hline & $\mathrm{C}$ & Preventing carpal collapse [8] & \\
\hline IV & & Salvage procedures $[14,50]$ & $\begin{array}{l}\text { - Total or limited wrist arthrodesis or total wrist } \\
\text { arthroplasty [14,50] } \\
\text { - PRC with dorsal wrist capsule arthroplasty [51] } \\
\text { + Additional wrist denervation can be beneficial in } \\
\text { symptom alleviation [52] }\end{array}$ \\
\hline
\end{tabular}

Proximal Row Carpectomy (PRC) is an old but still effective salvage procedure provided that the capitate head is well-preserved and the lunate fossa of the radius is in perfect condition [56]. Dorsal capsule interposition can also be performed in patients with mild arthritic changes of the capitate [51]. However, a recent randomized trial suggests that a dorsal capsule flap does not improve the range of motion and functional range in PRC [57]. Numerous studies with long-term follow-up of a minimum of 10 years have demonstrated that PRC is a reliable long-term treatment approach for stage III and IV Kienböck disease [44-46]. Nonetheless, the use of PRC in stage IV cases should be limited due to the risk of early degeneration of capitate and radius articular surfaces. PRC with distal radius hemiarthroplasty is a novel procedure dedicated to patients with wrist arthritis [58].

One of the most recent surgical techniques used in Stage III Kienböck cases is Vascularized Bone Grafting (VBG). Until now, the pedicled osseous grafts have been transposed from the ulna, ulnar shaft, pisiform, radial metaphysis, and scaphoid [59-64]. Moreover, free vascularized bone transfers from the medial femoral condyle and iliac crest have been described $[1,65,66]$. The most significant component of these procedures includes the preparation of tension-free vascular pedicles, which include nutrient vessels supplying both cancellous and cortical parts of the bone [67]. The majority of follow-up or postoperative studies demonstrated excellent reduction of pain, increased wrist mobility, and 
improvement of strength [68]. In particular, the long-term effects of free vascularized iliac bone transfer in a late-stage Kienböck's disease study found a major improvement in the flexion-extension arc, grip strength, pain, DASH score, Green O'Brien score, and Stahl index [1]. Bone marrow transfusion from distal radius or iliac crest combined with low-intensity pulsed ultrasound may be a less invasive alternative to VBG, with promising results regarding pain and functional score six years after the procedure $[49,69]$.

Another perspective method in late-stage Kienböck's disease is vascularized capitate transposition +/ - capitate osteotomy combined with the vascularized bone transfer (Figure 4). Short-term follow-up studies demonstrated promising clinical results, but longterm follow-up results are still required [47,48].

Lunate excision performed alone or preferably combined with STT provided pain relief and improvement in wrist mobility. Nevertheless, the tendency of scaphoid shifting towards lunate fossa was observed [70]. Lunate replacement techniques were also developed, using silicone, titanium, pyrocarbon, or 3D printed prostheses with a view to stabilizing the wrist and preserving its mobility $[67,71,72]$. 3D printed, personalized prostheses show favorable results in short to mid-term follow-ups of preliminary studies [73]. However, the use of these methods is limited owing to the lack of long-term follow-up studies and the inherent instability of prostheses [67]. Lunate excision with replacement could be particularly beneficial in Lichtman stage IIIC cases when coronal plane split and partial lunate collapse occur without the possibility of revascularization or reconstruction. However, modification to lunate replacement methods is required to obtain satisfactory clinical outcomes [14]. Arthroscopic excision of the lunate without replacement may be a viable alternative for low-demand patients in need of clinical and functional improvement in the short to mid-term [74]. Inevitable complications in a longer follow-up period limit the use of this method across other patient populations.

\subsection{Stage IV}

In this stage, due to total lunate collapse with nonfunctional radioscaphoid articulation and advanced arthritic changes in the capitolunate joint, the wrist is often no longer reconstructable. Therefore, salvage procedures in stage IV are preferred. These procedures include limited or total wrist arthrodesis and total wrist arthroplasty [14,50]. Alternatively, PRC with dorsal wrist capsule arthroplasty can be performed. Nonetheless, advanced arthritic changes may lead to failure of this procedure and reduced grip strength [51]. Additional wrist denervation can be beneficial in symptom alleviation. A long-term study of patients with stage IV Kienböck disease, with an average of 9.6 years follow-up, proved that complete wrist denervation resulted in subjective improvement in two-thirds of patients. Approximately one-half of the patients admitted complete or considerable alleviation of pain [52]. There are also a limited number of described late-stage disease cases (including one patient with stage IV) treated with total lunectomy and lunate replacement with a 3D printed, personalized, titanium-alloy lunate prosthesis [73]. 


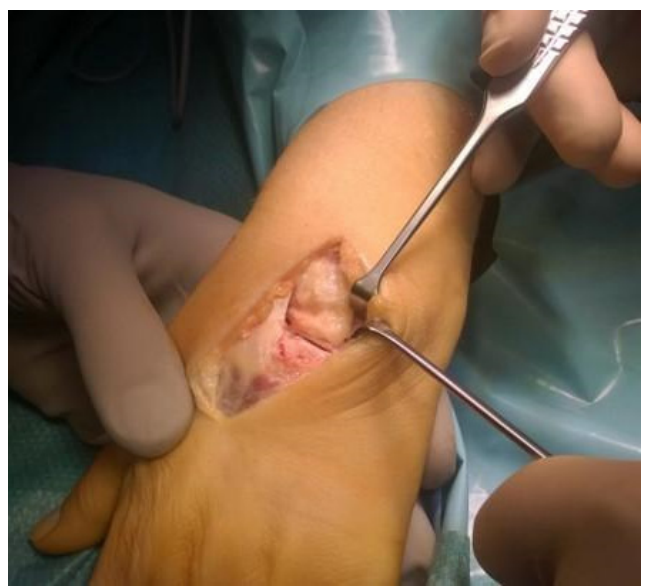

(a)

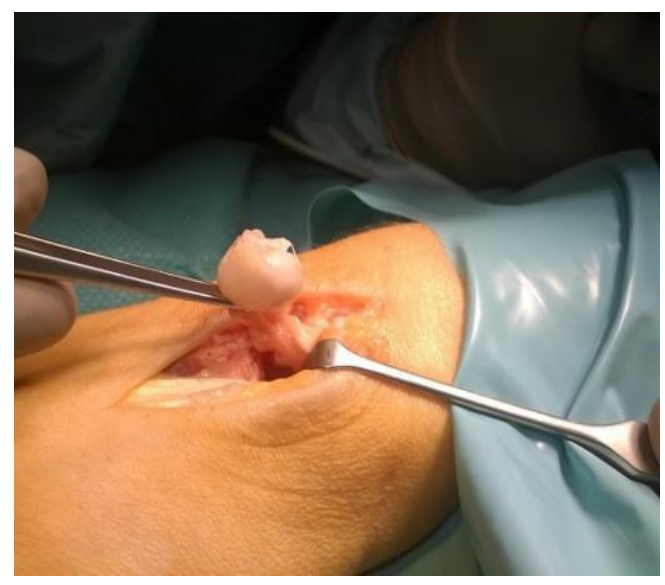

(b)

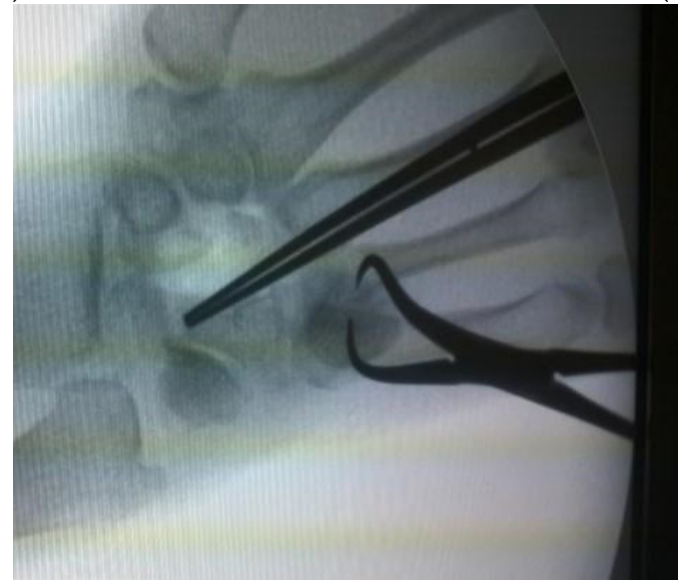

(c)

Figure 4. Photographs were obtained during surgery in a patient undergoing vascularized capitate transposition and capitate osteotomy combined with the vascularized bone transfer (modified Granner's method). (a) A view of the anatomy of the radiolunate joint fully exhibited using a dorsal surgical approach; (b) Vascularised capitate graft being harvested; (c) X-ray of the wrist after lunate excision and transposition of the capitate.

\section{Adjuvant Procedures}

A handful of additional procedures can be performed autonomously or in combination with other described procedures to improve the outcome of treatment [67]. Arthroscopic or open synovectomy is especially beneficial, considering that synovitis is one of the typical findings in Kienböck's disease [8,9]. Avik et al. also proposed arthroscopic debridement and arthrolysis as alternative treatment options for salvage procedures in late-stage disease. These treatment approaches resulted in excellent pain management but failed to show a significant increase in wrist motion and grip strength [75]. Furthermore, temporary STT joint fixation can unload the lunate, thus promoting revascularization. This procedure is applied primarily in conjunction with VBG and as the first-choice procedure in teenage patients with Kienböck's disease [53,76]. Recently, the use of cultured autologous multipotent mesenchymal stromal cells in Kienböck's disease was reported. However, this method is in the experimental stage and its long-term effectiveness is unknown [77].

\section{Summary}

The ideal treatment for different stages of Kienböck's is still under debate. Furthermore, clear guidelines based on randomized multicenter, controlled studies are missing. Choosing the right treatment method is clinically demanding for hand surgeons. The algorithm should depend primarily on the clinical symptoms, radiological evaluation, and 
the surgeon's experience. The Lichtman scale is the most common radiological classification used to describe Kienböck's disease. Proper classification of the disease is essential and is the main determinant in choosing the right treatment for a patient with osteonecrosis of the lunate. However, the choice of procedure should also take into account anatomical and personal factors. Based on retrospective data, no management of Kienböck's disease has sufficient data to determine that the intervention outcomes are the most effective. This review explored the advantages and disadvantages of the available up-to-date treatment options and their matching to the best indications. At the earliest stages of Kienböck disease, nonoperative management is predominantly advised. The main goal in treating stage II is revascularization, unloading, and decompression of the lunate. Stage IIIA often requires lunate reconstruction, while IIIB and IIIC frequently involve partial wrist arthrodesis. Salvage procedures such as wrist arthrodesis are limited mainly to Lichtman IV.

Funding: This research received no external funding.

Institutional Review Board Statement: Not applicable.

Informed Consent Statement: Not applicable.

Data Availability Statement: Not applicable.

Conflicts of Interest: The authors declare that they have no conflict of interest.

\section{References}

1. Arora, R.; Lutz, M.; Deml, C.; Krappinger, D.; Zimmermann, R.; Gabl, M. Long-term subjective and radiological outcome after reconstruction of Kienböck's disease stage 3 treated by a free vascularized iliac bone graft. J. Hand Surg. Am. 2008, 33, 175-181. [CrossRef] [PubMed]

2. Fontaine, C. Kienböck's disease. Chir. Main 2015, 34, 4-17. [CrossRef] [PubMed]

3. Facca, S.; Gondrand, I.; Naito, K.; Lequint, T.; Nonnenmacher, J.; Liverneaux, P. Graner's procedure in Kienböck disease: A series of four cases with 25 years of follow-up. Chir. Main 2013, 32, 305-309. [CrossRef] [PubMed]

4. Van Leeuwen, W.F.; Janssen, S.J.; ter Meulen, D.P.; Ring, D. What Is the Radiographic Prevalence of Incidental Kienböck Disease? Clin. Orthop. Relat. Res. 2016, 474, 808-813. [CrossRef] [PubMed]

5. White, C.; Benhaim, P.; Plotkin, B. Treatments for Kienböck disease: What the radiologist needs to know. Skeletal Radiol. 2016, 45, 531-540. [CrossRef] [PubMed]

6. Lluch, A.; Garcia-Elias, M. Etiology of Kienböck disease. Tech. Hand Up. Extrem. Surg. 2011, 15, 33-37. [CrossRef] [PubMed]

7. Alsanawi, H. Surgical interventions for Kienbock's disease: An update. J. Health Spec. 2017, 5, 12. [CrossRef]

8. Beredjiklian, P.K. Kienböck's disease. J. Hand Surg. Am. 2009, 34, 167-175. [CrossRef]

9. Bain, G.I.; Begg, M. Arthroscopic assessment and classification of Kienbock's disease. Tech. Hand Up. Extrem. Surg. 2006, 10, 8-13. [CrossRef]

10. Bain, G.I.; Durrant, A. An articular-based approach to Kienbock avascular necrosis of the lunate. Tech. Hand Up. Extrem. Surg. 2011, 15, 41-47. [CrossRef]

11. Schmitt, R.; Heinze, A.; Fellner, F.; Obletter, N.; Strühn, R.; Bautz, W. Imaging and staging of avascular osteonecroses at the wrist and hand. Eur. J. Radiol. 1997, 25, 92-103. [CrossRef]

12. Kennedy, C.; Abrams, R. In Brief: The Lichtman Classification for Kienböck Disease. Clin. Orthop. Relat. Res. 2019, 477, 1516-1520. [CrossRef] [PubMed]

13. Lichtman, D.M.; Lesley, N.E.; Simmons, S.P. The classification and treatment of Kienbock's disease: The state of the art and a look at the future. J. Hand Surg. Eur. Vol. 2010, 35, 549-554. [CrossRef] [PubMed]

14. Lichtman, D.M.; Pientka, W.F., II; Bain, G.I. Kienböck disease: A new algorithm for the 21st century. J. Wrist Surg. 2017, 6, 2-10. [CrossRef]

15. DeGeorge, B.R.J.; Chawla, S.S.; Lewallen, L.; Kakar, S. Functional and radiographic disease progression in nonoperatively managed Kienböck disease. Plast. Reconstr. Surg. 2021, 147, 1117-1123. [CrossRef]

16. Raven, E.E.J.; Haverkamp, D.; Marti, R.K. Outcome of Kienböck's disease 22 years after distal radius shortening osteotomy. Clin. Orthop. Relat. Res. 2007, 460, 137-141. [CrossRef]

17. Watanabe, T.; Takahara, M.; Tsuchida, H.; Yamahara, S.; Kikuchi, N.; Ogino, T. Long-term follow-up of radial shortening osteotomy for Kienbock disease. J. Bone Jt. Surg. Am. 2008, 90, 1705-1711. [CrossRef]

18. Quenzer, D.E.; Dobyns, J.H.; Linscheid, R.L.; Trail, I.A.; Vidal, M.A. Radial recession osteotomy for Kienböck's disease. J. Hand Surg. Am. 1997, 22, 386-395. [CrossRef]

19. Daecke, W.; Lorenz, S.; Wieloch, P.; Jung, M.; Martini, A.-K. Vascularized os pisiform for reinforcement of the lunate in Kienböck's disease: An average of 12 years of follow-up study. J. Hand Surg. Am. 2005, 30, 915-922. [CrossRef]

20. Tillberg, B. Kienboeck's disease treated with osteotomy to lengthen ulna. Acta Orthop. Scand. 1968, 39, 359-369. [CrossRef] 
21. Trail, I.A.; Linscheid, R.L.; Quenzer, D.E.; Scherer, P.A. Ulnar lengthening and radial recession procedures for Kienböck's disease. Long-term clinical and radiographic follow-up. J. Hand Surg. Br. 1996, 21, 169-176. [CrossRef]

22. Trumble, T.; Glisson, R.R.; Seaber, A.V.; Urbaniak, J.R. A biomechanical comparison of the methods for treating Kienböck's disease. J. Hand Surg. Am. 1986, 11, 88-93. [CrossRef]

23. Žiger, T.; Kopljar, M.; Bakota, B.; Milošević, M.; Kondža, G.; Pavić, R.; Čoklo, M. Experimental shortening of the radius in the treatment of Kienböck's disease. Injury 2021, 52 (Suppl. 5), S7-S10. [CrossRef]

24. Kolovich, G.P.; Kalu, C.M.K.; Ruff, M.E. Current trends in treatment of Kienböck disease: A survey of hand surgeons. Hand 2016, 11, 113-118. [CrossRef] [PubMed]

25. Bhardwaj, P.; Varadharajan, V.; Godora, N.; Sabapathy, S.R. Kienbock's disease: Treatment options-A search for the apt! J. Hand Surg. Asian-Pac. Vol. 2021, 26, 142-151. [CrossRef] [PubMed]

26. Wada, A.; Miura, H.; Kubota, H.; Iwamoto, Y.; Uchida, Y.; Kojima, T. Radial closing wedge osteotomy for Kienböck's disease: An over 10 year clinical and radiographic follow-up. J. Hand Surg. Br. 2002, 27, 175-179. [CrossRef] [PubMed]

27. Gay, A.M.; Parratte, S.; Glard, Y.; Mutaftschiev, N.; Legre, R. Isolated capitate shortening osteotomy for the early stage of Kienböck disease with neutral ulnar variance. Plast. Reconstr. Surg. 2009, 124, 560-566. [CrossRef]

28. Bain, G.I.; Smith, M.L.; Watts, A.C. Arthroscopic core decompression of the lunate in early stage Kienbock disease of the lunate. Tech. Hand Up. Extrem. Surg. 2011, 15, 66-69. [CrossRef]

29. Mehrpour, S.R.; Kamrani, R.S.; Aghamirsalim, M.R.; Sorbi, R.; Kaya, A. Treatment of Kienböck disease by lunate core decompression. J. Hand Surg. Am. 2011, 36, 1675-1677. [CrossRef]

30. Kamrani, R.S.; Najafi, E.; Azizi, H.; Oryadi Zanjani, L. Outcomes of arthroscopic lunate core decompression versus radial osteotomy in treatment of Kienböck disease. J. Hand Surg. Am. 2021. [CrossRef]

31. Schulz, C.U. Metaphyseal core decompression of the distal radius for early lunate necrosis. J. Hand Surg. Asian Pac. Vol. 2019, 24, 276-282. [CrossRef] [PubMed]

32. Illarramendi, A.A.; Schulz, C.; De Carli, P. The surgical treatment of Kienböck's disease by radius and ulna metaphyseal core decompression. J. Hand Surg. Am. 2001, 26, 252-260. [CrossRef] [PubMed]

33. Illarramendi, A.A.; De Carli, P. Radius decompression for treatment of kienböck disease. Tech. Hand Up. Extrem. Surg. 2003, 7, 110-113. [CrossRef] [PubMed]

34. Sevimli, R.; Ertem, K.; Aslanturk, O.; Ari, B. Midterm results of radial metaphyseal core decompression on Kienböck's disease. Eur. Rev. Med. Pharmacol. Sci. 2017, 21, 5557-5561. [CrossRef]

35. Bochud, R.C.; Büchler, U. Kienböck's disease, early stage 3-Height reconstruction and core revascularization of the lunate. J. Hand Surg. Br. 1994, 19, 466-478. [CrossRef]

36. Moran, S.L.; Cooney, W.P.; Berger, R.A.; Bishop, A.T.; Shin, A.Y. The use of the $4+5$ extensor compartmental vascularized bone graft for the treatment of Kienböck's disease. J. Hand Surg. Am. 2005, 30, 50-58. [CrossRef]

37. Nakagawa, M.; Omokawa, S.; Kira, T.; Kawamura, K.; Tanaka, Y. Vascularized bone grafts from the dorsal wrist for the treatment of Kienböck disease. J. Wrist Surg. 2016, 5, 98-104. [CrossRef]

38. Tsantes, A.G.; Papadopoulos, D.V.; Gelalis, I.D.; Vekris, M.D.; Pakos, E.E.; Korompilias, A.V. The efficacy of vascularized bone grafts in the treatment of scaphoid nonunions and kienbock disease: A systematic review in 917 Patients. J. Hand Microsurg. 2019, 11, 6-13. [CrossRef]

39. Hong, I.-T.; Lee, S.; Jang, G.C.; Kim, G.; Han, S.-H. Kienböck's disease with non-negative ulnar variance: Treatment with combined radial wedge and shortening osteotomy. Orthopade 2019, 48, 96-101. [CrossRef]

40. De Carli, P.; Zaidenberg, E.E.; Alfie, V.; Donndorff, A.; Boretto, J.G.; Gallucci, G.L. Radius core decompression for Kienböck disease stage IIIA: Outcomes at 13 years follow-up. J. Hand Surg. Am. 2017, 42, 752.e1-752.e6. [CrossRef]

41. Higgins, J.P.; Bürger, H.K. Osteochondral flaps from the distal femur: Expanding applications, harvest sites, and indications. J. Reconstr. Microsurg. 2014, 30, 483-490. [CrossRef] [PubMed]

42. Watson, H.K.; Ryu, J.; DiBella, A. An approach to Kienböck's disease: Triscaphe arthrodesis. J. Hand Surg. Am. 1985, 10, 179-187. [CrossRef]

43. Bain, G.I.; Ondimu, P.; Hallam, P.; Ashwood, N. Radioscapholunate arthrodesis-A prospective study. Hand Surg. 2009, 14, 73-82. [CrossRef] [PubMed]

44. Croog, A.S.; Stern, P.J. Proximal row carpectomy for advanced Kienböck's disease: Average 10-year follow-up. J. Hand Surg. Am. 2008, 33, 1122-1130. [CrossRef]

45. Ali, M.H.; Rizzo, M.; Shin, A.Y.; Moran, S.L. Long-term outcomes of proximal row carpectomy: A minimum of 15-year follow-up. Hand 2012, 7, 72-78. [CrossRef]

46. Liu, M.; Zhou, H.; Yang, Z.; Huang, F.; Pei, F.; Xiang, Z. Clinical evaluation of proximal row carpectomy revealed by follow-up for 10-29 years. Int. Orthop. 2009, 33, 1315-1321. [CrossRef]

47. Lu, L.J.; Gong, X.; Wang, K.L. Vascularized capitate transposition for advanced Kienböck disease: Application of 40 cases and their anatomy. Ann. Plast. Surg. 2006, 57, 637-641. [CrossRef]

48. Li, J.; Pan, Z.; Zhao, Y.; Hu, X.; Zhao, X. Capitate osteotomy and transposition for type III Kienböck's disease. J. Hand Surg. Eur. Vol. 2018, 43, 708-711. [CrossRef] 
49. Ogawa, T.; Ochiai, N.; Nishiura, Y.; Tanaka, T.; Hara, Y. A new treatment strategy for Kienböck's disease: Combination of bone marrow transfusion, low-intensity pulsed ultrasound therapy, and external fixation. J. Orthop. Sci. Off. J. Jpn. Orthop. Assoc. 2013, 18, 230-237. [CrossRef]

50. Rauhaniemi, J.; Tiusanen, H.; Sipola, E. Total wrist fusion: A study of 115 patients. J. Hand Surg. Am. 2005, 30, 217-219. [CrossRef]

51. Salomon, G.D.; Eaton, R.G. Proximal row carpectomy with partial capitate resection. J. Hand Surg. Am. 1996, 21, 2-8. [CrossRef]

52. Schweizer, A.; von Känel, O.; Kammer, E.; Meuli-Simmen, C. Long-term follow-up evaluation of denervation of the wrist. J. Hand Surg. Am. 2006, 31, 559-564. [CrossRef] [PubMed]

53. Yajima, H.; Ono, H.; Tamai, S. Temporary internal fixation of the scaphotrapezio-trapezoidal joint for the treatment of kienbock's disease: A preliminary study. J. Hand Surg. Am. 1998, 23, 402-410. [CrossRef]

54. Van den Dungen, S.; Dury, M.; Foucher, G.; Marin Braun, F.; Loréa, P. Conservative treatment versus scaphotrapeziotrapezoid arthrodesis for Kienbock's disease. A retrospective study. Chir. Main 2006, 25, 141-145. [CrossRef]

55. Kleinman, W.B.; Carroll IV, C. Scapho-trapezio-trapezoid arthrodesis for treatment of chronic static and dynamic scapho-lunate instability: A 10-year perspective on pitfalls and complications. J. Hand Surg. Am. 1990, 15, 408-414. [CrossRef]

56. Green, D.P.; Perreira, A.C.; Longhofer, L.K. Proximal row carpectomy. J. Hand Surg. Am. 2015, 40, 1672-1676. [CrossRef]

57. Fukushima, W.Y.; De Moraes, V.Y.; Penteado, F.T.; Faloppa, F.; Dos Santos, J.B.G. Does dorsal capsule interposition improve the results of proximal row carpectomy in Kienböck's disease? One year randomized trial. SICOT-J 2015, 1, 25. [CrossRef]

58. Culp, R.W.; Bachoura, A.; Gelman, S.E.; Jacoby, S.M. Proximal row carpectomy combined with wrist hemiarthroplasty. J. Wrist Surg. 2012, 1, 39-46. [CrossRef]

59. Mir, X.; Barrera-Ochoa, S.; Lluch, A.; Llusa, M.; Haddad, S.; Vidal, N.; Font, J. New surgical approach to advanced Kienböck disease: Lunate replacement with pedicled vascularized scaphoid graft and radioscaphoidal partial arthrodesis. Tech. Hand Up. Extrem. Surg. 2013, 17, 72-79. [CrossRef]

60. Tan, Z.; Xiang, Z.; Huang, F.; Yang, Z.; Xiao, C.; Duan, X. Long-term results of vascularized os pisiform transfer for advanced Kienböck disease after follow-up for at least 15 years A case series. Medicine 2018, 97, e13229. [CrossRef]

61. Matsumoto, T.; Kakinoki, R.; Ikeguchi, R.; Ohta, S.; Akagi, M.; Matsuda, S. Vascularized bone graft to the lunate combined With temporary scaphocapitate fixation for treatment of stage III Kienböck disease: A report of the results, a minimum of 2 years after surgery. J. Hand Surg. Am. 2018, 43, 773.e1-773.e7. [CrossRef] [PubMed]

62. Shin, A.Y.; Bishop, A.T. Pedicled vascularized bone grafts for disorders of the carpus: Scaphoid nonunion and Kienbock's disease. J. Am. Acad. Orthop. Surg. 2002, 10, 210-216. [CrossRef] [PubMed]

63. Zaidemberg, C.; Siebert, J.W.; Angrigiani, C. A new vascularized bone graft for scaphoid nonunion. J. Hand Surg. Am. 1991, 16, 474-478. [CrossRef]

64. Heymans, R.; Adelmann, E.; Koebke, J. Anatomical bases of the pediculated pisiform transplant and the intercarpal fusion by graner in Kienböck's disease. Surg. Radiol. Anat. 1992, 14, 195-201. [CrossRef] [PubMed]

65. Doi, K.; Oda, T.; Soo-Heong, T.; Nanda, V. Free vascularized bone graft for nonunion of the scaphoid. J. Hand Surg. Am. 2000, 25, 507-519. [CrossRef]

66. Doi, K.; Sakai, K. Vascularized periosteal bone graft from the supracondylar region of the femur. Microsurgery 1994, 15, 305-315. [CrossRef]

67. Bain, G.I.; Yeo, C.J.; Morse, L.P. Kienböck Disease: Recent advances in the basic science, assessment and treatment. Hand Surg. 2015, 20, 352-365. [CrossRef]

68. Fujiwara, H.; Oda, R.; Morisaki, S.; Ikoma, K.; Kubo, T. Long-term results of vascularized bone graft for stage III Kienböck disease J. Hand Surg. Am. 2013, 38, 904-908. [CrossRef]

69. Ogawa, T.; Ochiai, N.; Hara, Y. Bone marrow from the iliac crest versus from the distal radius for revitalizing the necrotic lunate for Kienböck disease. J. Hand Surg. Eur. Vol. 2020, 45, 299-301. [CrossRef]

70. Lee, J.S.; Park, M.J.; Kang, H.J. Scaphotrapeziotrapezoid arthrodesis and lunate excision for advanced kienböck disease. J. Hand Surg. Am. 2012, 37, 2226-2232. [CrossRef]

71. Viljakka, T.; Tallroth, K.; Vastamäki, M. Long-term clinical outcome after titanium lunate arthroplasty for Kienböck disease. J. Hand Surg. Am. 2018, 43, 945.e1-945.e10. [CrossRef] [PubMed]

72. Xie, M.-M.; Tang, K.-L.; Yuan, C.-S. 3D printing lunate prosthesis for stage IIIc Kienböck's disease: A case report. Arch. Orthop. Trauma Surg. 2018, 138, 447-451. [CrossRef] [PubMed]

73. Ma, Z.; Liu, Z.; Shi, Q.; Li, T.; Liu, Z.; Yang, Z.; Liu, Y.; Xu, Y.; Dai, K.; Yu, C.; et al. Varisized 3D-printed lunate for Kienböck's disease in different stages: Preliminary results. Orthop. Surg. 2020, 12, 792-801. [CrossRef] [PubMed]

74. Shimizu, T.; Omokawa, S.; Kawamura, K.; Nakanishi, Y.; Onishi, T.; Nagashima, M.; Hasegawa, H.; Kurata, S.; Tanaka, Y. Arthroscopic lunate excision provides excellent outcomes for low-demand patients with advanced Kienböck disease. Arthrosc. Sport. Med. Rehabil. 2021, 3, e1387-e1394. [CrossRef]

75. Ayik, O.; Demirel, M.; Turgut, N.; Altas, O.; Durmaz, H. Arthroscopic debridement and arthrolysis for the treatment of advanced Kienböck's dsease: 18-month and 5-year postoperative results. J. Wrist Surg 2021, 10, 280-285. 
76. Ando, Y.; Yasuda, M.; Kazuki, K.; Hidaka, N.; Yoshinaka, Y. Temporary scaphotrapezoidal joint fixation for adolescent Kienböck's disease. J. Hand Surg. Am. 2009, 34, 14-19. [CrossRef]

77. Ikeguchi, R.; Aoyama, T.; Kakinoki, R.; Ueda, M.; Kasai, Y.; Maekawa, T.; Tada, H.; Yamamoto, M.; Matsuda, S.; Nakamura, T.; et al. A clinical trial for Kienböck disease by cultured autologous multipotent mesenchymal stromal cells augmented with vascularized bone grafts: A report of five cases. J. Orthop. Sci. 2019, 24, 750-756. [CrossRef] 